\title{
Objective Evaluation Model of Visual Elegance of Swirl Skirts Part ( I ) Regression Method
}

\author{
SANG-SONG Lai \\ Department of Apparel, National Pintung University of Science and Technology, Taiwan, R.O.C.
}

Received; 17 April 2002 ; Accepted for Publicatiion 16 November 2002

\begin{abstract}
The elegant impression of swirl skirts has been well received by most ladies, yet the textile industry does not have an objective method of evaluating the visual elegance of swirl skirt by grades. In the present study we there for use fabric mechanical properties through the KES-FB system to predict the elegance of swirl skirt manufactured that is to create a method for objectively evaluating visual elegance of swirl skirt by grades. From the study it is found there is a notable correlation between fabric mechanical properties and the visual elegance of swirl skirt by grades. It can also establish a objective evaluation model of visual elegance of swirl skirt by grades basing on the regression method using several key fabric mechanical properties, in which the said models pass the fitting test with results exceeding 0.80 . In addition, in the present study we use stepwise regression selection method to pick out the most significant key factors ( bending rigidity and shear hysteresis at $0.5^{\circ}$ ) affecting the visual elegance of swirl skirt by grades and then reapplies the regression method successfully thus establishing a method only using two fabric mechanical properties for objective evaluation of the visual elegance of swirl skirt by grades, in a more simple and objective manner.
\end{abstract}

Key words: Visual elegance of swirl skirts, Objective evaluation model, KES-FB system, Mechanical properties, Regression

\section{Introduction}

The swirl design of skirts, in terms of appearance, its elegant and soft appearance has always been appealing women and the center of focus in the fashion world. However in order to display the elegant rhythm, it must start with the selection of cloth materials for swirl skirt, in which the design stage usually plays an extremely important role. However up still now the textile industry lacks a set objective evaluation method for dynamic evaluation of the visual appearance of swirl skirt. When fashion designers start to design swirl skirts, they are often faced with the following problems:

- They cannot obtain fabric property information from textile makers, so how can their determine if a fabric is suitable for the swirl skirts design?

- Present-day garment designers or garments buyers often rely on personal subjective experience to select their swirl skirts fabrics. This method is neither scientific nor objective; moreover, they have a difficulty passing on this experience to another.

- The beauty of the swirl skirts design is determined through subjective opinions. The textile makers, garments manufacturers and garments retailers lack an objective "consensus" about what makes a beautiful swirl skirts design. Hence communication problems can easily arise due to their background differences.

- To date, designers have a very limited choice of fabrics. Despite their dissatisfaction with the swirl skirts created, they cannot effectively communicate their disappointment to the textile makers. Even if the textile makers alter fabric production to meet the swirl skirts perfection requirements, they do not have the objective fabric property data, and hence they are incapable of improving

* Corresponding author Fax: 08-7740146, E-mail: ss1@mail.npust.edu.tw 
their production or fabric properties to meet such requirements.

As garment manufacturing becomes more automated, it has become possible to use several key fabric mechanical properties to predict garment quality. The inability to effectively control the relationship between fabric properties and the swirl skirts design aesthetics has become the greatest obstacle of garment production automation.

From previous research papers, the writer learned the mechanical properties of cloth materials obviously have their influence on the external appearance of the clothing produced [1-5]. Therefore, it is the question of how to use the values of some key properties of fabrics for making an objective prediction whether the fabrics can be made into a swirl skirt with elegance appearance. This has been the expectation of garment and textile industries. In order to achieve this goal, in the present study we apply the regression method and artificial neural network to establish a prediction system using fabric mechanical properties to obtain objective values with regard to the dynamic visual appearance of swirl skirt. It is our hope that the commonly accepted fabric mechanical properties can be used to replace the evaluation of visual appearance of swirl skirt currently practiced by the textile industry, that is to make the original subjective evaluation more objective, so as to establish a common language for the appearance of swirl skirt that can be shared by the textile and garment industries. In addition, with the creation of the prediction system, the textile industry could amend their process parameters for manufacturing fabrics and change mechanical properties of cloth materials, thus producing the kind of cloth materials suitable for making visually elegant swirl skirts.

\section{Research Methodology}

\subsection{Experiment material}

The test samples used in this paper are the microfibre and regenerated fiber, as they are the most suitable among the fabrics currently sold in the market for the swirl skirts design. During the sampling stage, we talked to the fabric designer of 12 textile makers in Taiwan. Then they selected around 10 to 15 pieces of fabrics they manufactured for the swirl skirts design, thus coming up with a total of 136 samples. We gave each sample a code and selected 60 samples using the random sampling method. These served as our study specimen. We only selected light colored samples; gray and white, to ensure that no fabric color differentiation shall affect the swirl skirts effect evaluation. Sample properties are tabulated in Table 1.

\subsection{Measuring the fabric mechanical properties}

This paper used the Kawabata's evaluation system for fabric (KES-FB) to measure the 16 mechanical properties of the fabrics. The parameter definitions and statistics value are shown in Table 2, where the predicted scope of the objective evaluation model is provided.

Table 1 Details of fabric samples

\begin{tabular}{|l|l|l|l|l|l|}
\hline Properties & $\begin{array}{l}\text { Polyester } \\
\text { Nylon }\end{array}$ & Tencel & $\begin{array}{l}\text { Model } \\
\text { rayon }\end{array}$ & $\begin{array}{l}\text { Cotton/ } \\
\text { Model }\end{array}$ & $\begin{array}{l}\text { Cotton/ } \\
\text { Tencel }\end{array}$ \\
\hline $\begin{array}{l}\text { Fiber content } \\
(\%)\end{array}$ & $60-80 /$ & 100 & 100 & $\begin{array}{l}20-30 / \\
80-70\end{array}$ & $\begin{array}{l}20-30 / \\
80-70\end{array}$ \\
\hline Sample number & 20 & 8 & 12 & 11 & 9 \\
\hline End per cm & $10-12$ & $10-14$ & $10-14$ & $11-14$ & $11-14$ \\
\hline Picks per cm & $9-11$ & $9-14$ & $10-12$ & $11-12$ & $10-14$ \\
\hline Yarn count (Tex) & $11-15$ & $9-12$ & $10-12$ & $10-13$ & $9-14$ \\
\hline Weave & Twill & Twill & Twill & Twill & Twill \\
\hline
\end{tabular}

Table 2. Characteristic values of basic mechanical properties

\begin{tabular}{|c|c|c|c|c|c|}
\hline Symbols & $\begin{array}{l}\text { Characteristics value } \\
\text { (Unit) }\end{array}$ & Min. & Max. & Mean & S.D. \\
\hline LT & $\begin{array}{l}\text { Linearity } \\
\text { (Non) }\end{array}$ & 0.512 & 1.123 & 0.824 & 0.152 \\
\hline WT & $\begin{array}{l}\text { Tensile energy } \\
\left(\mathrm{gf} \quad \mathrm{cm} / \mathrm{cm}^{2}\right)\end{array}$ & 0.101 & 4.238 & 2.726 & 1.198 \\
\hline RT & $\begin{array}{l}\text { Resilience } \\
(\%)\end{array}$ & 34.812 & 57.813 & 47.361 & 5.575 \\
\hline B & $\begin{array}{l}\text { Bending rigidity } \\
\left(\mathrm{gf}^{\cdot} \mathrm{cm}^{2} / \mathrm{cm}\right)\end{array}$ & -1.050 & 0.955 & 0.237 & 0.429 \\
\hline $2 \mathrm{HB}$ & $\begin{array}{l}\text { Hysteresis } \\
\left(\mathrm{gf}^{\cdot} \mathrm{cm}^{2} / \mathrm{cm}\right)\end{array}$ & -1.320 & 0.992 & 0.397 & 0.724 \\
\hline G & $\begin{array}{l}\text { Shear stiffness } \\
\left(\mathrm{gf} / \mathrm{cm}{ }^{\circ} \text { degree }\right)\end{array}$ & 0.210 & 11.020 & 4.792 & 3.749 \\
\hline $2 \mathrm{HG}$ & $\begin{array}{l}\text { Hysteresis at } 0.5^{\circ} \\
(\mathrm{gf} / \mathrm{cm})\end{array}$ & 0.373 & 32.910 & 10.006 & 7.690 \\
\hline $2 \mathrm{HG} 5$ & $\begin{array}{l}\text { Hysteresis at } 5^{\circ} \\
(\mathrm{gf} / \mathrm{cm})\end{array}$ & 1.011 & 29.010 & 12.081 & 6.508 \\
\hline M IU & $\begin{array}{l}\text { Coefficientof friction } \\
\text { (Non) }\end{array}$ & 0.112 & 0.472 & 0.250 & 0.081 \\
\hline M M D & $\begin{array}{l}\text { Mean deviation of MIU } \\
\text { (Non) }\end{array}$ & 0.011 & 0.043 & 0.028 & 0.008 \\
\hline SM D & $\begin{array}{l}\text { Geometrical roughness } \\
\text { (micron) }\end{array}$ & 0.891 & 12.980 & 4.812 & 2.638 \\
\hline $\mathrm{LC}$ & $\begin{array}{l}\text { Linearity } \\
\text { (Non) }\end{array}$ & 0.236 & 0.781 & 0.40 & 0.143 \\
\hline W C & $\begin{array}{l}\text { Compressional energy } \\
\left(\mathrm{gf}^{\cdot} \mathrm{cm} / \mathrm{cm}^{2}\right)\end{array}$ & 0.033 & 0.990 & 0.284 & 0.150 \\
\hline $\mathrm{RC}$ & \begin{tabular}{|l|}
$\begin{array}{l}\text { Resilience } \\
(\%)\end{array}$ \\
\end{tabular} & 31.120 & 59.710 & 48.370 & 6.492 \\
\hline$T$ & $\begin{array}{l}\text { Thickness at } 0.5 \mathrm{gf} / \mathrm{cm}^{2} \\
(\mathrm{~mm})\end{array}$ & 0.037 & 1.497 & 0.971 & 0.344 \\
\hline W & $\begin{array}{l}\text { Weight per unit area } \\
\left(\mathrm{Mg} / \mathrm{cm}^{2}\right)\end{array}$ & 10.120 & 46.710 & 32.90 & 8.813 \\
\hline
\end{tabular}

\subsection{Swirl skirt design and manufacture}

Swirl skirt is a kind of ring-shaped cut, such as swirl-like, to emphasize the undulating effect of swirl silhouette and the swinging of ripples below from waistline. It is particularly suitable for wearing by ladies, whose pattern is depicted in Figure1. 


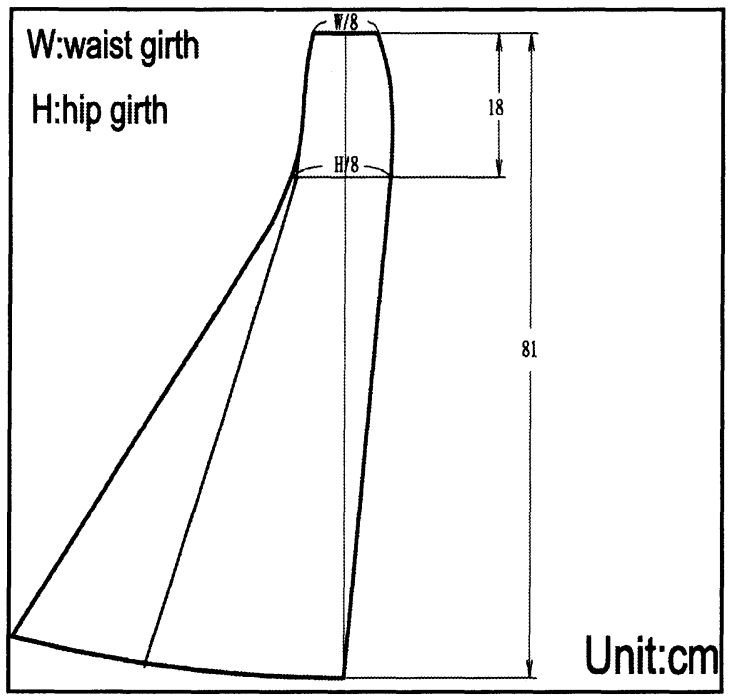

Figure 1 Swirl skirt pattern

\subsection{The subjective evaluation of visual elegance of swirl skirt by grades}

In the present study we perform the tests under nature light and a single girl model is hired to wear 60 different swirl skirts, strolling back and forth on the catwalk for experts to grade their respective visual elegance according to standard classifications such as flowing rhythm, harmony, visual equilibrium, naturalness of draping, and entire impression [6]. Each standard item counts for $20 \%$ of the score. Evaluators graded the fabrics based on the look of the swirl skirt. There was a total of 10 grade categories ranging from the most beautiful effect, then gradually reducing in scale to the least beautiful effect. The 5-person evaluator team included designers, garment merchandise planners and marketing experts with seniority in swirl skirt designing, creation and sales experience. A judges meeting was held before evaluation was conducted, so a consensus may be created concerning the swirl skirt look evaluation criteria and implications. The evaluation of the 60 sets of swirl skirt designs followed.

\subsection{Uniform test}

Despite the vast practical experiences of the swirl skirt experts invited for this study, the evaluating consensus obtained during the judges meeting aimed to achieve a judging coherence. It was hoped that the judging should be free from emotional and other personal factors; hence, we verified the coherence of the evaluation grade values. The purpose was to screen out the experts that were not stable. The evaluation results were significantly different from the evaluation made by majority of the experts, since we seek to obtain coherence in the swirl skirt look evaluation. The verification method: First, the swirl skirt effect evaluation of 15 experts were placed under the Friedman two-way analysis of variance by ranks. If no coherence was noted, then the Wilcoxon signed-rank test was used to find the incoherent swirl skirt evaluation for disqualification [7]. The coherent evaluators were chosen through the aforementioned method, then the average value of the grading values used by these experts to evaluate the swirl skirt appearance was obtained. It became the swirl skirt grading value of the samples.

\subsection{Objective evaluation model}

In the present study we apply the regression methods to establish a transformation model using the fabric mechanical properties for predicting the visual elegance of swirl skirt by grades. It employs both the forced enter and the stepwise selection methods. In doing so the SPSS 10.0 statistics software is adopted. The main purpose of the regression method is to make a prediction that corresponds with the target of the present study. In order to find out the correlation between fabric mechanical properties and subjective visual elegance of swirl skirt by grades, we uses 16 fabric mechanical parameters as independent variables and average grade in subjective visual of swirl skirt as response variables in the process of the regression analysis. In addition, in order to understand whether after screening out some independent variables it can proceed with the evaluation of swirl skirt elegance, so we perform the analysis with the stepwise regression selection method, while the fitting capability of the regression model used is to be judged by whether the residual plot is presented in a random manner, where residual value be small; $\mathrm{R}^{2}$ (R-square) be large; MES (Mean of square) be small; and P value $<0.0001$ as the criterion.

\section{Conclusions and Discussions}

\subsection{The subjective grading of the swirl skirt appearance}

This paper used statistics to establish a set of curve swirl skirt appearance evaluation method. Since aesthetic appreciation is a subjective pursuit, the key to the success of this paper lies in the objectivity of the swirl skirt evaluation and the coherence of the evaluators' ratings. First, the 60 curve swirl skirt grades made by the 15 experts $(\mathrm{N})$ were analyzed through the Friedman two-way analysis of variance by ranks; findings are as tabulated in Table 3 . The significance $P$ value is 0.0001 and chi-square value is 43.5481; hence a significant difference existed between the subjective swirl skirt evaluations of the 15 experts. Their perceptions are not coherent. To identify the differences and match evaluations, we obtained the average grading value of the 15 experts and conducted difference verification between that value and the individual grading value of each expert. Findings are tabulated in Table 4. It showed that in the case of experts $\mathrm{A}, \mathrm{B}, \mathrm{C}, \mathrm{I}$ and $\mathrm{K}$, the grading value and average grade is $P$ value $<0.05$, achieving the significant difference level. The swirl skirt look opinions of these 5 experts were not coherent with the majority opinion; hence their opinions 
were disqualified. These 5 experts were: 1 fashion designer, 2 garments merchandise planner, and 2 garments marketing personnel. A random distribution was noted. Next, the grades made by the 10 other experts were placed under the Friedman two-way analysis of variance by ranks. Findings are tabulated in Table 3. A P value of 0.4791 signifies that after the removal of the unstable 5 experts, judgment was quite coherent. Results of the Wilcoxon signed-rank test conducted are tabulated in Table 4. It was found that the average evaluation of the 10 experts and the $P$ value of the individual evaluation of each expert were both $p$ value $>0.05$. In other words, the 10 experts had a very coherent opinion concerning the swirl skirt view. The subjective grading of each swirl skirts are shows in Table 5.

Table 3 Friedman two-way analysis of variance by ranks

\begin{tabular}{|c|l|l|l|}
\hline Experts & Chi-square & Df & P value \\
\hline 15 & 43.548 & 14 & $0.0001^{*}$ \\
\hline 10 & 8.557 & 9 & 0.4791 \\
\hline
\end{tabular}

*:P value $<0.01$ (significant at the 0.01 level)
Table 4 Wilcoxon signed-rank test

\begin{tabular}{|c|l|l|l|l|}
\hline \multirow{2}{*}{$\begin{array}{l}\text { Experts } \\
\text { mar }\end{array}$} & \multicolumn{2}{|c|}{ Z value } & \multicolumn{2}{c|}{ P value } \\
\cline { 2 - 5 } & $\mathrm{N}=15$ & $\mathrm{~N}=10$ & $\mathrm{~N}=15$ & $\mathrm{~N}=10$ \\
\hline $\mathrm{A}$ & -3.051 & $\sim$ & $0.0023^{*}$ & $\sim$ \\
\hline $\mathrm{B}$ & -2.379 & $\sim$ & $0.0174^{*}$ & $\sim$ \\
\hline $\mathrm{C}$ & -2.636 & $\sim$ & $0.0084^{*}$ & $\sim$ \\
\hline $\mathrm{D}$ & -1.084 & -1.438 & 0.2784 & 0.1505 \\
\hline $\mathrm{E}$ & -1.383 & -1.771 & 0.1667 & 0.0765 \\
\hline $\mathrm{F}$ & -0.529 & -0.11 & 0.5969 & 0.9127 \\
\hline $\mathrm{G}$ & -0.986 & -0.688 & 0.3243 & 0.4913 \\
\hline $\mathrm{H}$ & -1.771 & -1.369 & 0.0765 & 0.1710 \\
\hline $\mathrm{I}$ & -2.565 & $\sim$ & $0.0103^{*}$ & $\sim$ \\
\hline $\mathrm{J}$ & -0.464 & -1.134 & 0.6425 & 0.2568 \\
\hline $\mathrm{K}$ & -2.410 & $\sim$ & $0.0160^{*}$ & $\sim$ \\
\hline $\mathrm{L}$ & -0.627 & -0.222 & 0.5307 & 0.8244 \\
\hline $\mathrm{M}$ & -1.839 & -1.617 & 0.0659 & 0.1059 \\
\hline $\mathrm{N}$ & -0.910 & -0.697 & 0.3628 & 0.4857 \\
\hline $\mathrm{O}$ & -0.704 & -0.367 & 0.4817 & 0.7138 \\
\hline P Value & $<0.01$ & & & \\
\hline
\end{tabular}

Table 5 The average grading of swirl skirts appearance by the 10 experts

\begin{tabular}{|l|l|l|l|l|l|l|l|l|l|l|l|l|l|l|l|}
\hline No & 1 & 2 & 3 & 4 & 5 & 6 & 7 & 8 & 9 & 10 & 11 & 12 & 13 & 14 & 15 \\
\hline Grading & 6.21 & 7.01 & 6.18 & 6.5 & 4.01 & 6.32 & 3.2 & 5.2 & 3.65 & 5.02 & 5.6 & 3.21 & 7.0 & 7.01 & 6.91 \\
\hline No & 16 & 17 & 18 & 19 & 20 & 21 & 22 & 23 & 24. & 25 & 26 & 27 & 28 & 29 & 30 \\
\hline Grading & 3.44 & 8.6 & 7.6 & 8.33 & 8.4 & 7.01 & 5.03 & 5.0 & 5.0 & 5.0 & 5.39 & 6.55 & 7.0 & 4.0 & 3.81 \\
\hline No & 31 & 32 & 33 & 34 & 35 & 36 & 37 & 38 & 39 & 40 & 41 & 42 & 43 & 44 & 45 \\
\hline Grading & 6.3 & 7.33 & 8.05 & 4.9 & 5.32 & 6.0 & 6.33 & 4.03 & 7.88 & 7.44 & 8.01 & 8.61 & 8.91 & 9.01 & 5.61 \\
\hline No & 46 & 47 & 48 & 49 & 50 & 51 & 52 & 53 & 54 & 55 & 56 & 57 & 58 & 59 & 60 \\
\hline Grading & 4.6 & 6.4 & 6.5 & 5.01 & 5.4 & 5.3 & 7.3 & 4.11 & 5.6 & 6.43 & 7.5 & 8.01 & 5.91 & 6.22 & 7.0 \\
\hline
\end{tabular}

Table 6 Matrix of correlation coefficient

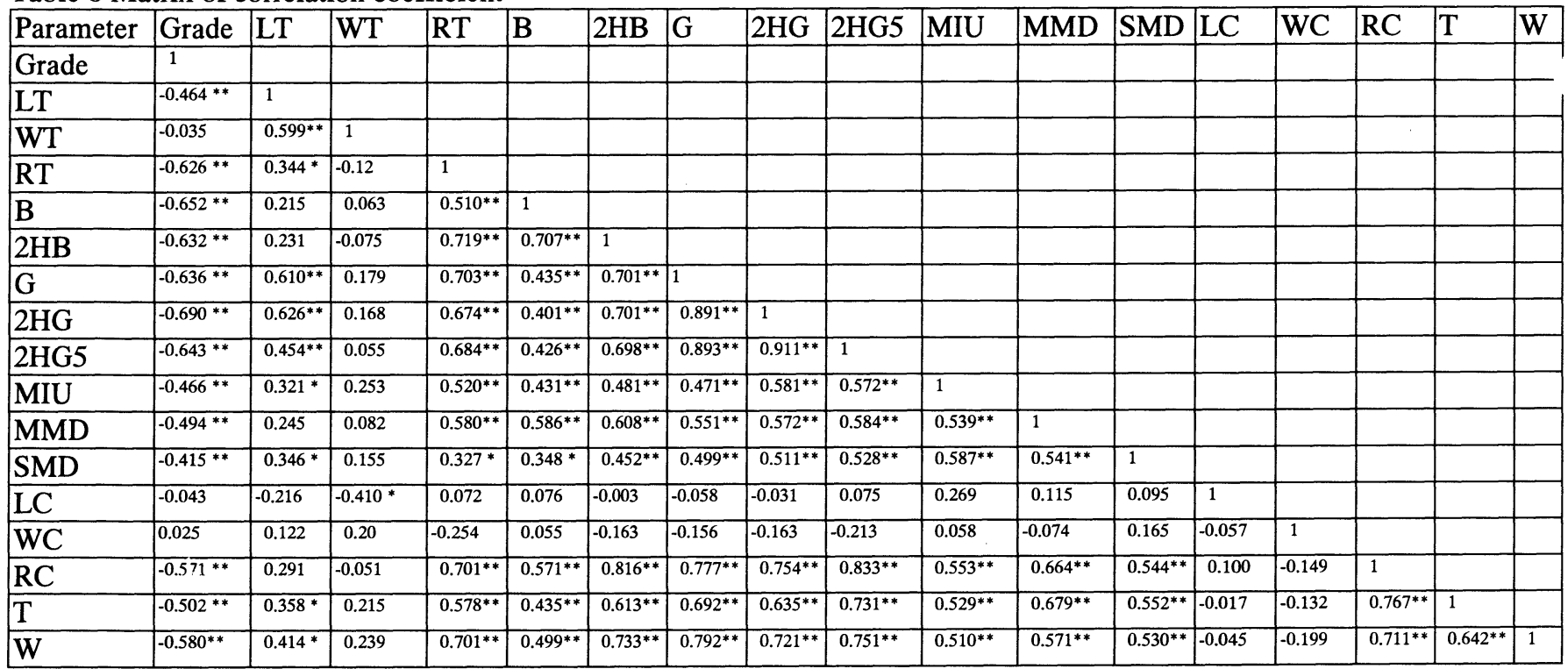

$*: \mathrm{P}<0.01 ;{ }^{*} \mathrm{P}<0.001$

\subsection{Correlation analysis}

In this section we use the related analysis to explore the correlation between the 16 fabric mechanical parameters themselves and between the 16 mechanical parameters and the elegance of swirl skirt by grades. From Table 6 it is discovered, except for WT, LC and WC, the visual elegance grade of swirl skirt and 13 other fabric mechanical parameters all exhibit notable correlation $(\mathrm{P}$ value $<0.05)$, and the correlation are trending negatively. Among them, the ones with correlation coefficient $(r>0.50)$ are the 9 items: 
2HG, B, 2HG5, G, 2 HB, RT, W, RC and T. Again some mechanical parameters exhibit rather high correlation between each other, for those with correlation coefficient above 0.80 include: 2HG-2HG5, G-2HG5, G-2HG, 2HG5-RC, and 2HB-RC. The ones with correlation coefficient reaching $0.60-0.80$ include: $\mathrm{LT}$ and G; $2 \mathrm{HG}$, RT and 2HB; G; 2HG; 2HG5; RC; W, B and 2HB, 2HB and G; 2HG; 2HG5; MMD; RC; T; W, G and RC; T; W, 2HG and RC; T; W, 2HG5 and T; W, MMD and RC; T, RC and T; W, and $\mathrm{T}$ and $\mathrm{W}$ etc. However these kinds of results are reflected in the selection of stepwise regression model parameters.

\subsection{Regression analysis}

In this section we apply the regression method to establish the model for transformation from fabric mechanical parameters to subjective visual elegance of swirl skirt by grades, that is to use fabric mechanical parameter for predicting the visual elegance of fabrics used in making swirl skirts. For forced enter method it establishes the regression model such that $Y=6.1267-0.2116(L T)+0.4823$ (WT) $-0.3102(\mathrm{RT})-0.9597(\mathrm{~B})+0.3891(2 \mathrm{HB})+0.3051(\mathrm{G})-.21$ 81 (2HG)+0.1788 (2HG5)+0.0386(MIU)+0.3038(MMD) -0 . 0753 (SMD) +0.0285(LC) -0.0802 (WC) + 0.5163 (RC)

$-0.4401(T)-0.2390(W)$, where $Y$ : visual elegance of swirl skirt by grades; LT, WT, RT, B, 2HB, 2HG, 2HG5, MIU, MMD, SMD, LC, WC, RC, T, and W: fabric mechanical properties. Their meanings are illustrated in Table 2. From Table 6 and Figure 2 we see Sig. F value 0.00001, R-square is 0.734 , and practical elegance value (subjective) of swirl skirt and prediction value (objective) exhibit high correlation, with correlation coefficient of 0.842 , reflecting that the regression model established by this study has good prediction capacity.

It is discovered from above description even though employing forced enter method to establish the regression model can obtain very good fitting capacity, it requires 16 mechanical parameters for the model, an tremendous numbers. Therefore it is an essential task to establish a simple and objective model for evaluating visual elegance of swirl skirt with small numbers of parameters basing on statistical method. Therefore, in the present study we select the stepwise regression selection method, which uses partial $\mathrm{F}$ test criterion to evaluate all fabric mechanical parameters for their contribution to the regression model, trying to find those key parameters that can increase the explication capacity of the regression model when added to the regression model. Those parameters with minimal contribution to the prediction of visual elegance of swirl skirt, or those mechanical parameters leading to the prediction results that exhibit high interchangeability among them selves will be eliminated in the process. The remaining key fabric mechanical parameters are adequate to produce effective prediction of visual elegance of swirl skirt.

The parameter selection process was carried out using a stepwise regression selection method. The method was used to determine the most obvious parameter directly affecting the visual elegance value of swirl skirts. Under the condition of $P_{\text {out }} 0.1$ and $P_{\text {in }} 0.05$ significant level and after two steps of stepwise regression analysis, objective swirl skirt visual elegance can be obtained from the stepwise regression model, such that the formula becomes: $Y=6.1267-0.6767$ (B) -0.7745 (2HG), where $Y$ is elegance of swirl skirt by grades; B is fabrics bending stiffness; and $2 \mathrm{HG}$ is shear stress hysteresis of fabrics at 0.5 degree shearing. From Table 7 and Figure 3 we discover the $\mathrm{R}$-square is 0.644 , and that the practical value and prediction value of swirl skirt both spread within the diagonal line of the diagram. Furthermore the correlation coefficient reaches a high of 0.803 , reflecting the model has high fitting capacity. There for we can say the parameters of the transformation model greatly affecting the objective elegance of swirl skirt by grades are two items: B and 2HG. Though from Table 6 , fabric mechanical parameters (RT, $2 \mathrm{HB}, \mathrm{G}, 2 \mathrm{HG} 5, \mathrm{RC}, \mathrm{T}$ and $\mathrm{W}$ ) and elegance of swirl skirt by grades exhibit high correlation, they are not included in the model selection due to the reason that these parameters have high degree of collinear relation with $\mathrm{B}$ and $2 \mathrm{HG}$, that is to say they are interchangeable, such as $\mathrm{B}$ and $2 \mathrm{HB} \quad(\mathrm{r}=0.707) ; \mathrm{RC}$ $(\mathrm{r}=0.571), 2 \mathrm{HG}$ and RT $(\mathrm{r}=0.674) ; \mathrm{G}(\mathrm{r}=0.891) ; 2 \mathrm{HG} 5$ $(\mathrm{r}=0.911) ; \mathrm{T}(\mathrm{r}=0.635) ; \mathrm{W}(\mathrm{r}=0.721)$. Therefore, in the present study we successfully establish a method of evaluating the visual elegance of swirl skirt only using two mechanical parameters.

Table 7 Analysis of variance for model

\begin{tabular}{|l|l|l|l|l|l|}
\hline \multirow{2}{*}{} & Model & DF & \multicolumn{2}{|l|}{ Mean square } & F \\
\hline \multirow{2}{*}{ Regression } & Enter & 16 & 99.402 & 6.212 & 7.413 \\
\cline { 2 - 5 } & Stepwise & 2 & 87.236 & 43.618 & 51.619 \\
\hline \multirow{2}{*}{ Residual } & Enter & 43 & 36.034 & 0.838 & \\
\cline { 2 - 5 } & Stepwise & 57 & 48.200 & 0.845 & \\
\hline
\end{tabular}

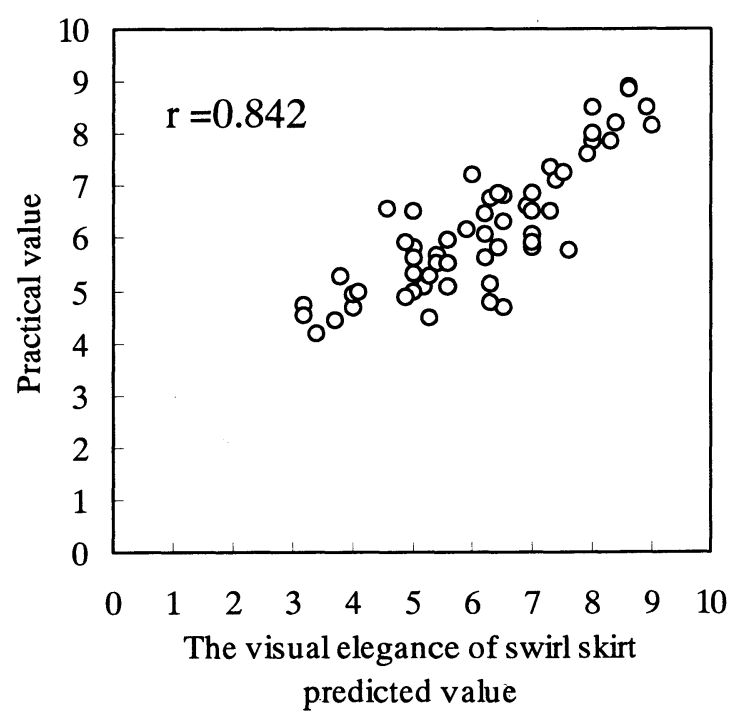

Figure 2 Scatter plot of by forced enter model 


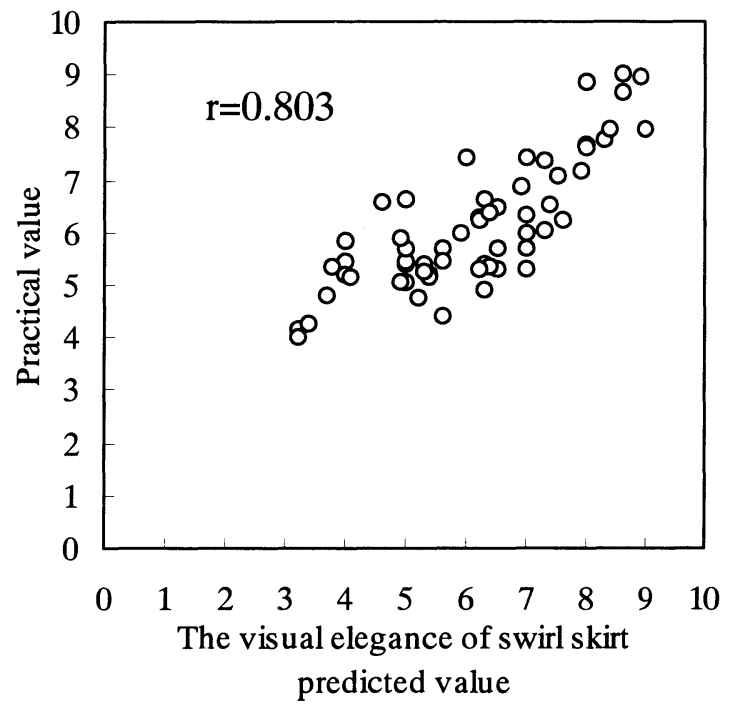

Figure 3 Scatter plot of by stepwise model
[6]. Lai, S.S., J. Sci. \& Tech., 10(6), pp.459-469, (2001)

[7]. Lai, S.S., J. Jpn. Res. Assn. Text. End-Uses, 42(10), pp.649-656, (2001)

[8]. Zhang, X., Li, Y. and Yeung, K.W., Textile Res. J., 67(7), pp.511-518, (1999)

\section{Conclusion}

From our study we discover, besides WT, LC and WC, 13 among 16 fabric mechanical properties of the KES- FB system are confirmed to have notable influence on the elegance of swirl skirt. In the present study we succeeded in establishing an objective evaluation method based on several key fabric mechanical properties and the transformation model from fabric mechanical properties to elegance by grades of swirl skirt, no matter it employs the forced enter or stepwise selection method. They all have the superior prediction capacity, yet the forced enter model is better than stepwise selection method. Especially the model established by stepwise selection method that used only two key parameters (B and $2 \mathrm{HG}$ ) to effectively predict the visual elegance of $\mathrm{s}$ xirl skirt by grades. Its prediction capacity exceeds 0.80 , yet the average residual value between the model prediction value and subjective elegance value of swirl skirt is only within 0.7 grade, reflecting that this method indeed possesses the characteristics of more simple and convenient to use, objective and effective. In order to find the elegance model that possesses an even well be fitting ability, neural network will be applied in the following studies.

\section{References}

[1]. Jinlial H. and Chan Y. F., Textile Res. J., 68(1), pp.57-64, (1998)

[2]. Collier, B. J., Clothing Textiles J., 9, pp.46-52, (1991)

[3]. Ascough, J., Bez, H. E., and Bricis, A., Int. J. Clothing Sci. Tech.,8(3), pp.59-74, (1996)

[4]. Niwa, M., and Morooka, H., J. Textile Machin. Soc. Jpn., 22(3), pp.67-73, (1976)

[5]. Kawabata, S., and Niwa, M., J. Textile Inst., 80, pp.19-50, (1989) 